\title{
PURIFICATION OF THE YELLOW FLUORESCENT PROTEIN FROM VIBRIO FISCHERI AND IDENTITY OF THE FLAVIN CHROMOPHORE
}

\author{
P. Macheroux, K.U. Schmidt, P. Steinerstauch, and S. Ghisla \\ Faculty of Biology, University of Konstanz, POB 5560, \\ D-7750 Konstanz, FRG \\ P. Colepicolo, R. Buntic, and J.W. Hastings, \\ Department of Cellular and Developmental Biology, \\ Harvard University, Cambridge, MA 02138
}

A low molecular weight protein ( $\sim 25,000$ D) exhibiting a yellow fluorescence emission peaking at $\sim 540 \mathrm{~nm}$ was isolated from Vibrio fischeri (strain Y-1) and purified to apparent homogeneity. FMN is the chromophore, but it exhibits marked red shifts in both the absorption $\left(\lambda_{\max }=380,460 \mathrm{~nm}\right)$ and the fluorescence emission. When added to purified luciferase from the same strain, which itself catalyzes an emission of blue-green light ( $\left.\lambda_{\max } \sim 495 \mathrm{~nm}\right)$, this protein induces a bright yellow luminescence ( $\lambda_{\max } \sim 540 \mathrm{~nm}$ ); this corresponds to the emfssion of the $Y-1$ strain in vivo. This yellow bioluminescence emission is thus ascribed to the interaction of these two proteins, and to the excitation of the singlet FMN bound to this fluorescent protein.

The light emission of bioluminescent bacteria is characteristically centered in the blue-green region, with a maximum at about $495 \mathrm{~nm}$ (1). About ten years ago, however, Ruby and Nealson (2) reported a strain of Photobacterium (formerly Vibrio) fischeri isolated from sea water off San Dicgo that emitted yellow light. Spectrally, two maxima were observed: one at the usual $495 \mathrm{~nm}$ and a second in the yellow about $540 \mathrm{~nm}$.

This yellow emission was later identified with a yellow fluorescent protein, distinct from luciferase, but capable of generating the yellow bioluminescence when included in a luciferase in vitro reaction system otherwise emitting blue light (3). The chromophore appeared to be a flavin, but netther its identity nor the purification and properties of this novel protein were reported. In view of the keen interest in the mechanism of populating excited states in chemi- and bioluminescence (4), as well as the identity of the emitcer(s) in the bacterial luciferase system $(1,5-9)$, we undertook a detalled study of this yellow fluorescent protein (YFP).

\section{MATER IALS AND METHODS}

Instrumentation and Assay: Bioluminescence was measured with a calibrated photomultiplier photometer (10). Fluorescence excitation and emission 
spectra were recorded with a Perkin Elmer MPF4 spectrophotofluorimeter; the spectral composition of bioluminescence was measured in the same instrument without the exciting 1ight. Bioluminescence and fluorescence emission spectra were corrected for wavelength dependent differences in sensitivity. Absorption spectra were measured with the Kontron Uvicon 820 spectrophotometer. SDS-PAGE was carried out according to Laemmli (11) with protein molecular weight standards from Pharmacia. The standard buffer contained $10 \mathrm{mM} \mathrm{K} / \mathrm{Na}$ phosphate, $\mathrm{pH}$ 7.0, with $1 \mathrm{mM}$ dithiothreitol, $1 \mathrm{mM}$ EDTA and $1 \mu \mathrm{M}$ FMN (Sigma). All chemicals used were of analytical (or best avallable) grade and not further purified.

The activity of luciferase alone, without regard for the color of the light emitted, was measured photometrically at $22^{\circ}$ in the "dithionite" assay (14), in which luciferase and FMN are first reduced with dithionite and the reaction is initiated by the rapid mixing with long chain aldehyde and excess oxygen. In this reaction the half time of the light emission is quite short, perhaps $10-20 \mathrm{~s}$, too short for easy measurement of its spectral distribution. The activity of the YFP was estimated by measuring the intensity of the yellow ( $~ 540 \mathrm{~nm}$ ) band relative to the blue in a luciferase assay at $12^{\circ} \mathrm{C}$. To do this the coupled reductase-luciferase assay (12) was used, in which FMN is reduced by NADH (Sigma) via added flavin reductase (13); with excess NADH assay light emission may be caused to continue much longer. The reaction mixture ( $150 \mu 1$ final volume) included $10 \mu 1$ of a purified luciferase $(\sim 50 \mu \mathrm{M}) ; 10 \mu 1$ of purified reductase $(\sim 50 \mu \mathrm{M}) ; 10 \mu \mathrm{I}$ FMN $(0.4 \mathrm{mM}) ; 10 \mu \mathrm{l}$ decanal suspension $(0.01 \% \mathrm{v} / \mathrm{v}) ; 100 \mu 1$ of the sample in standard buffer; and $10 \mu 1$ of NADH $(0.1$ $M)$ to infifate the reaction in a microcuvette thermostatted at $12^{\circ}$ in the fluorimeter. Under these conditions the light emission was steady for up to 10 min.

Ce11 Growth and Harvesting: Vibrio fischeri, strain Y-1 (ATCC \#33715) was obtained from Dr. K.H. Nealson and grown at $1^{\circ}$ in a 2501 New Brunswick fermenter, in a complete sea water medium containing peptone and yeast extract (14). Cell density (by $\mathrm{OD}_{660 \mathrm{~nm}}$ ) and bioluminescence (photometrically) were monitored during growth; at peak luminescence (about $18 \mathrm{hr}$ ) the culture was rapidly cooled to $4^{\circ} \mathrm{C}$ and cells were harvested with a Braun continuous centrifuge. The resulting paste, about $500 \mathrm{~g}$ (wet weight) per 1801 culture, was frozen and stored at $-20^{\circ}$.

\section{RESULTS AND DISCUSSION}

Cells were lysed at $4^{\circ} \mathrm{C}$ in standard buffer $(600 \mathrm{ml} / 100 \mathrm{~g}$ cells $)$ with stirring for $1 \mathrm{hr}$. The lysate was centrifuged at $27,500 \mathrm{x}$ for $60 \mathrm{~min}$ and the precipitate discarded. Solid ammonium sulfate was added to the supernatant and the fraction precipitating between 40 and $75 \%$ saturation was dissolved in a minimal amount ( $100 \mathrm{ml}$ ) of standard buffer and dialyzed 3 times against the same buffer. This solution was combined with a DEAE-Sephacel suspension ( 80 $\mathrm{ml}$ ); after one hour the solid with the adsorbed protein was separated by centrifugation, packed into a column $(18 \mathrm{x} 2.5 \mathrm{~cm})$ and eluted with a gradient of the standard buffer with the phosphate concentration ranging from 10 to 300 $\mathrm{mM}$. The fractions were assayed for the different activities; those containing the YFP, as detected by the shift in fluorescence emission to longer wavelengths (see below), were combined and concentrated by ultrafiltration (Amicon $P M$ 10) to $20 \mathrm{ml}$. This was loaded on a Sephacryl $\mathrm{s}-200$ column $(90 \times 6 \mathrm{~cm})$ and the fractions containing YFP were eluted with standard buffer and applied to a 
HA-Ultrogel (hydroxyl-apatite, BioRad) column $(27 \times 2.5 \mathrm{~cm})$. The standard buffer without EDTA with a phosphate gradient (10-50 mM) was used to elute the YFP activity; active fractions were pooled, and concentrated by dialysis against polyethylene glycol to a volume of about $20 \mathrm{ml}$. YFP concentrations were measured in terms of flavin absorbance assuming one flavin per protein molecule.

For luciferase and flavin reductase, the material obtained from the 40$75 \%\left(\mathrm{NH}_{4}\right)_{2} \mathrm{SO}_{4}$ fractionation was dialyzed and subjected to gel filtration over Sephacry1 S-200; the two activities were well separated and were pooled separately. Luciferase was further purified according to the procedure of Holzman and Baldwin (15); FMN reductase was concentrated and used without further purification.

Several difficulties were encountered in the purification of YFP, notably the apparent denaturation of the protein. Considering that this might be due to the dissociation of the flavin chromophore, FMN $(1.0 \mu M)$ was added to all buffers used in the purification procedures. This appeared to be successful and the YFP protein was obtained in a purity estimated to be $>95 \%$ by by SDSPAGE (Figure 1). Based on the standards, a molecular weight of about 25,000 Daltons was estimated. Amino acid analysis gave a similar value.

The purified holoprotein exhibits the two absorption bands in the visible and near UV typical of a flavoprotein (Figure 2), but differs in some respects. Whereas the 440 and $375 \mathrm{~nm}$ flavin bands are usually only slightly shifted in flavoenzymes, these bands are red-shifted in YFP, probably due to a decrease in the protein polarity around the flavin binding region $(16,17)$. Moreover, the ratio of the peak absorbances of these two bands is 0.95 , whereas in free FMN it is 1.2 . The fluorescence emission maximum of the protein bound flavin is at $542 \mathrm{~nm}$ compared to about $525 \mathrm{~nm}$ for free flavin, but the fluorescence quantum yield is essentially unaltered.

The flavin chromophore associated with YFP was identified unambiguously as FMN by several independent criteria. Upon denaturation of the protein, elther by heat or by the addition of SDS, the chromophore exhibits the same absorption and fluorescence values as authentic FMN. Its $R_{f}$ value on thin layer chromatography (butano1:HAc: $\mathrm{H}_{2} \mathrm{O} ; 12: 3: 5$ ) and the retention time on HPLC (18) are identical with those of authentic FMN. This flavin can be used by bacterial luciferase, which is highly specific for FMN in the bioluminescence reaction $(1,7)$. It is bound by the FMN specific apoflavodoxin from Megasphera elsdenii (19), and also by riboflavin binding protein (which binds riboflavin and FMN, but not FAD) (20). Similar results were obtained in all of these tests utilizing YFP isolated and purified in the absence of added FMN. 

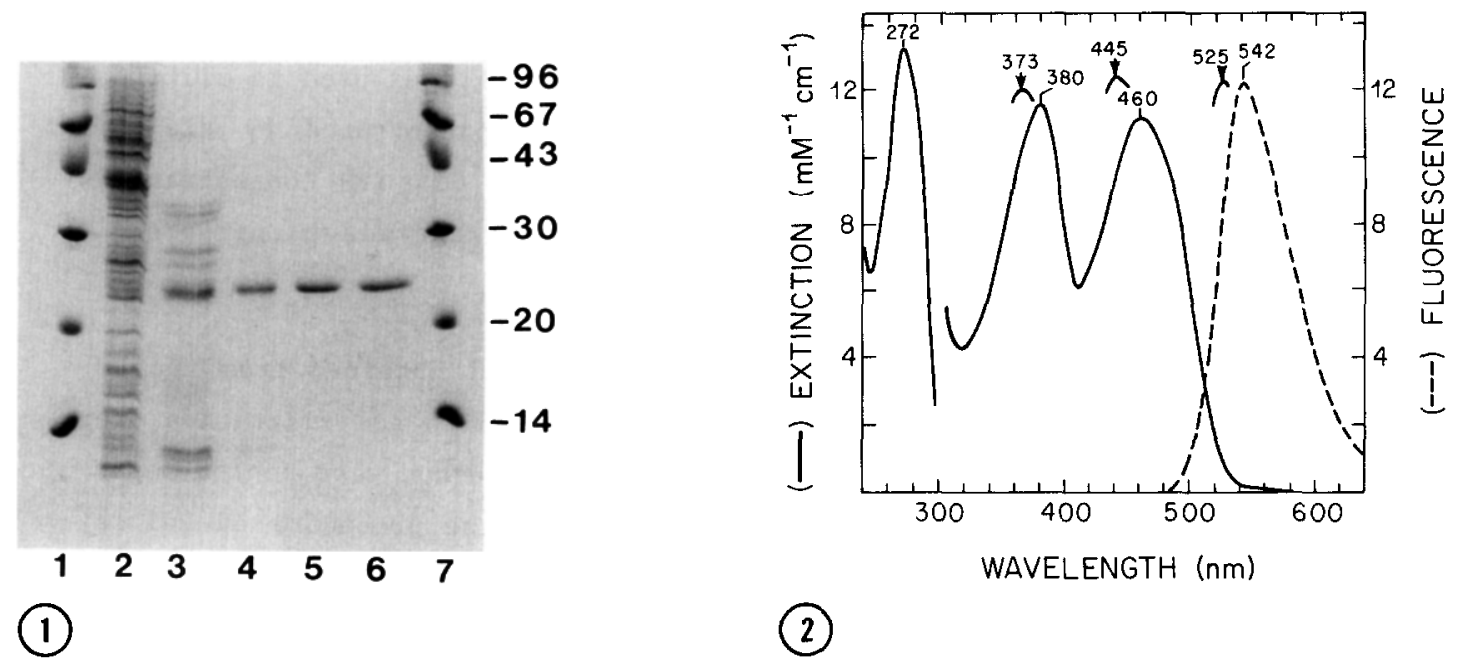

Figure 1. SDS-PAGE with $15 \%$ polyacrylamide. Lanes 1 and 2 , standards, with approximate molecular weights indicated in kilodaltons: $\alpha-$ lactalbumin $(14,000$ D), soybean trypsin inhibitor $(20,000$ D), carbonic anhydrase $(30,000$ D), Ovalbumin $(43,000$ D), bovine serum albumin $(67,000$ D), and phosphorylase $b(96,000 \quad \mathrm{D})$. Tane 2: crude extract after lysis and dialysis. Lane 3 after DEAE-Sephacel. Lane 4, after Sephacryl S-200 gel filtration. Lanes 5 and 6 , after u1trogel hydroxyl-apatite chromatography.

Figure 2. Absorption spectrum of purified YFP (best fractions after ultroge1 hydroxyl-apatite chromatography), $5.6 \mu \mathrm{M}$ in $10 \mathrm{mM}$ Tris-HCl, pH 7.0 containing $1.0 \mu M$ FMN, (left, solid lines). The sample was dialyzed extensively against this buffer and the spectrum was recorded with buffer in the reference. For the U.V. band $(240-300 \mathrm{~nm})$ the scale is 5 times greater. The arrows indicate the absorption maxima obtained after addition of $0.05 \%$ SDS; these correspond to those of free FMN. Corrected fluorescence emission spectrum of YFP (dashed line, right) measured using the same sample as above with excitation at $470 \mathrm{mn}$ ( $\mathrm{slits}, 4 \mathrm{~mm}$ ). The fluorescence emission maximum observed after addition of SDS is shown by the arrow. The fluorescence excitation spectruin for YFP (not shown) corresponds to its absorption spectrum, and after denaturation to that of the free flavin. Fluorescence in arbitrary units.

The effect of pure YFP on the bioluminescence emission of bacterial luciferase is demonstrated in $\mathrm{Fig} .3$, where the appearance of a new emission band with a $\lambda_{\max }$ at about $540 \mathrm{~nm}$ is evident. The similarity of this emission to that observed in vivo indicates that the yellow fluorescent protein is involved in the generation of yellow light in the Y-1 strain of Vibrio fischeri. Although energy transfer from a primary excited state has been suggested as a mechanism (2), the direct excitation of YFP by an electron exchange mechanism has also been proposed $(1,8)$.

It seems likely that a second chromophore may be involved in bacterial bioluminescence in cases where the emission in vivo differs from that of the pure luciferase in vitro $(21,22)$. Indeed a low molecular weight protein with a tightly bound chromophore identified as 8-ribityllumazine has been isolated 


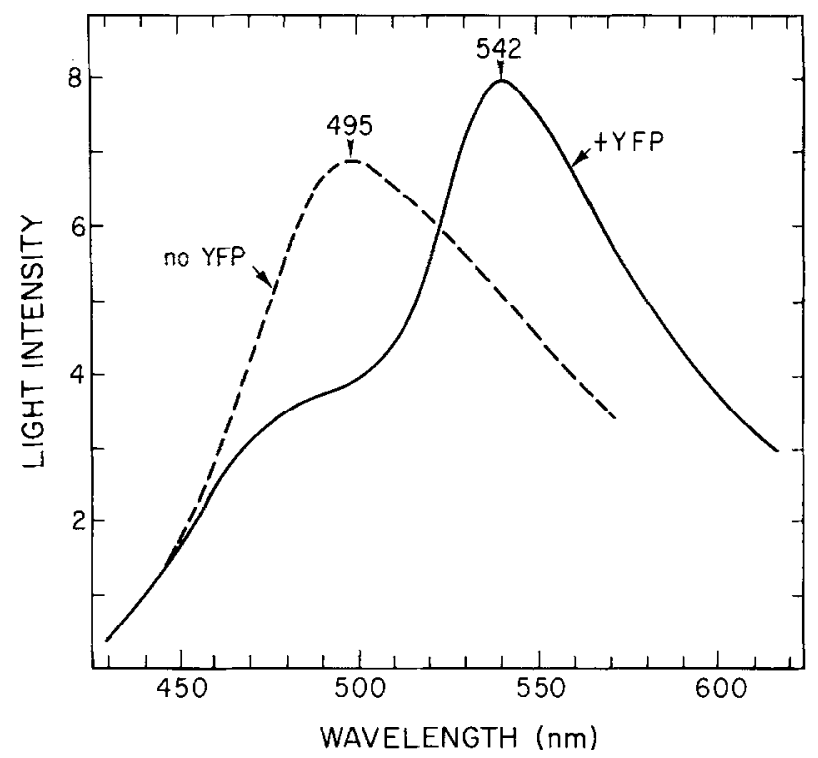

Figure 3. Comparison of the corrected bioluminescence emission spectra of the in vitro reactions with Vibrio Eischeri Y-1 luciferase in the absence (solid line, left) and in the presence of $5 \mu M$ YFP at $7^{\circ}$. Luminescence in arbitrary units.

from Photobacterfum phosphoreum and Photobacterium lelognathi (23) and shown to cause light emission to peak at $476 \mathrm{~nm}$, compared to $\sim 495 \mathrm{~nm}$ with luciferase alone. This is phenomenologically similar to the YFP protein: similar mechanisms for the population of the excited states may be involved.

\section{ACKNOWLEDGEMENTS}

This work was supported by a grant from the Deutsche Forschungsgemeinschaft to S.G. (DFG Gh $2 / 4-5,6$ ) and from the U.S. National Science Foundation to J.W.H. (DMB-8676522). P.C. was supported by a Brazilian National Research Council Fellowship ( $\mathrm{CNPq})$. We thank $\mathrm{Dr}$. K.H. Nealson for providing the bacterial strain and for helpful suggestions and discussion.

\section{RE FERENCE S}

1. Hastings, J.W., Potrikus, C.J., Gupta, S., Kurfürst, M., Makemson, J.C. (1985) Adv. Micro. Physiol. 26, 235-291.

2. Ruby, E.G. and Nealson, K.H. (1977) Science 196, 432-434.

3. Leisman, G. and Nealson, K.H. (1982) in Flavins and Flavoproteins (Massey, V., and Williams, C.H., eds.), Elsevier, New York, pp. 383-386.

4. Wilson, T. (1985) in Singlet oxygen (A.A. Frimer, ed.), Vo1. II, CRC Press, Inc., Boca Raton, FT, $\mathrm{pp}=37-65$.

5. Macheroux, P. and Ghisla, S. (1985) Nachr. Chem. Tech. Lab. 33, 785-790.

6. Lee, J. (1985) Chemi- and Bioluminescence (Burr, J.G., ed.), Plenum, New York, pp. 401-437.

7. Ziegler, , M.M. and Baldwin, T.0. (1981) Curr. Top. Bioenerg. 12, 65-113. 
8. Hastings, J.W. (1986) in Light Emission by Plants and Bacteria (Govindjee, J. Amesz and D.C. Fork, eds.), Academic Press, New York, pp. 363-398.

9. Kurfürst, M., Ghis1a, S. and Hastings, J.W. (1984) Proc. Nat. Acad. Sci. USA $81,2990-2994$.

10. Mitchell, G. and Hastings, J.W. (1971) Anal. Biochem. 39, 243-250.

11. Laemmli, U.K. (1970) Nature 227, 680-685.

12. Hastings, J.W., Baldwin, T.O. and Nicol1, M.Z. (1978) in Methods in Enzymology (Kaplan, N.O. and Colowick, S.P., eds.), Vol. 57 (M. De Luca, ed.), Academic Press, New York, pp. 135-152.

13. Watanabe, H. and Hastings, J.W. (1982) Mol. Cell Biochem. 44, 181-187.

14. Nealson, K.H. (1978) in Methods in Enzymology (Kaplan, N.O. and Colowick, S.P., eds.), Vol. 57 (M. De Luca, ed.), Academic Press, New York, pp. 153166 .

15. Holzman, T.F. and Baldwin, T.0. (1982) Biochemistry 21, 6194-6201.

16. Ghisla, S., Massey, V., Lhoste, J.M. and Mayhew, S.G. (1974) Biochemistry 13, 589-597.

17. Hel1is, P.F. (1982) Chem. Soc. Rev. 11, 15-39.

18. Ghisla, S., Massey, V. and Yag1, K. (1986) Biochemistry 25, 3282-3289.

19. Wassink, J.H. and Mayhew, S.G. (1975) Analytical Blochemistry 68, 609616 .

20. Becvar, J. and Palmer, G. (1982) J. Biol. Chem. 257, 5607-5617.

21. Seliger, H.H. and Morton, R.A. (1968) in Photophysiology (A.C. Giese, ed.), Vol. 4, Academic Press, NY pp. 253-314.

22. Matheson, I.B.C., Lee, J. and Müller, F. (1981) Proc. Nat1. Acad. Sci. USA 78, 948-952.

23. O'Kane, D.J., Karle, V.A. and Lee, J. (1985) Biochemistry 24, 1461-1467. 